\title{
Journals should lead the way in improving medical press releases
}

\author{
Joshua J Fenton
}

10.1136/eb-2014-101745

Department of Family and Community Medicine, University of California, Davis, California, USA

Correspondence to: Dr Joshua J Fenton, University of California, Davis 4860 Y St., Sacramento, CA 95817, USA;

joshua.fenton@ucdmc. ucdavis.edu
News stories about medical research influence patients' beliefs, behaviours and use of healthcare services. ${ }^{1}$ Yet the quality of news coverage of medical studies is often poor. ${ }^{2} 3$ Many news stories about medical research exaggerate the clinical significance of the findings, fail to report potential harms of new interventions or overlook important study limitations. ${ }^{2}$

While it is tempting to blame journalists for shoddy medical news coverage, academic researchers, their institutions and journals must share the blame. For scientists, news coverage is an opportunity to frame their research in a favourable light for the public and colleagues. Meanwhile, development and fund-raising exigencies demand that institutions generate public enthusiasm about scientific accomplishments, and medical editors are motivated to maximise the impact of the research published in their journals. Thus, researchers, institutions and journal editors share a common motivation to maximise press coverage of new medical research.

Not surprisingly researchers and their institutions commonly collaborate on press releases to promote news coverage of new medical studies, and many journals issue press releases independently. ${ }^{4}$ Press releases increase the odds that a study will receive news coverage $^{5}$ and influence the content of eventual press coverage. $^{6}$ Alarmingly, in the guise of original reporting, many press releases issued by academic institutions appear verbatim on newspapers and websites with nothing to notify readers that the text is nothing more than a press release.

Perhaps this would not be alarming if academic press releases reliably described research with appropriate circumspection and in terms easily comprehensible to lay readers. However, press releases commonly exaggerate the implications of study findings and offer quantitative information in formats that are prone to misinterpretation (eg, relative rather than absolute differences in treatment effects) without warning about study limitations. ${ }^{4}$ Thus, both the frequency and content of academic press releases contribute to public misunderstanding of medical science, with potentially serious public health consequences, notoriously illustrated by the sharp international declines in vaccination rates following subsequently retracted reports of the hazards of the measles-mumps-rubella vaccine. ${ }^{7}$

In light of the compelling personal and institutional motivations for issuing exaggerated press releases, what might investigators, institutions and journals do to improve news coverage of medical studies? Some have suggested that academic press releases should explicitly explain the limitations of the reported studies and should quantify both benefits and harms of interventions in absolute (not only relative) terms when feasible. $^{4}{ }^{6}$ Critics have also urged investigators and institutions to consider foregoing press releases if a study's immediate public health implications are uncertain, as is the case for most conference abstracts and many animal studies.

These insightful suggestions, however, do not adequately address the countervailing motivations for researchers, institutions and journals to issue exaggerated or misleading press releases. What is needed is a fundamental shift in investigators' and institutions' sense of obligation and responsibility when considering the issuance of press releases. Here is where major biomedical journals could take a leading role.

The Committee on Publication Ethics (COPE) asserts that biomedical journal editors have a duty to "maintain the integrity of the academic record. ${ }^{, 8}$ As such, COPE suggests that a best practice for journal editors is to ensure that 'press releases issued by their journal reflect the message of the reported article and put it into context. ' Resisting the allure of publicity, journals should begin by ensuring that journal press releases are reserved for studies with immediate public health importance and that the research findings are framed with appropriate caution.

However, journals also have the potential to influence the quality of press releases issued by authors and their institutions. As with conflicts of interest, major biomedical journals could issue consensus guidelines for academic press releases about published articles. The guidelines could be based on the needs and responsibilities of journalists, as articulated in the Principles of the Association of Health Care Journalists (http://healthjournalism.org/ secondarypage-details.php?id=56). ${ }^{9}$ First, the guidelines could specify what sort of studies are worthy of press releases. Human studies with immediate implications for patients' healthcare decisions and behaviours should be prioritised for press releases, while most animal research and human studies with surrogate outcomes should not. Second, the guidelines could specify what content should be included for studies of varying designs. For example, press releases for randomised trials should report both benefits and harms in absolute terms, while observational studies should clearly specify potentially confounding variables. Third, a key element of all press releases would be a clear explanation of study limitations and the extent of the study's generalisability to current practice. Copyright transfer agreements between authors and journals could also stipulate that authors must obtain journal approval of any press releases drafted by authors or institutions.

Consensus guidelines on academic press releases might improve the quality while reducing the quantity of press releases, making it easier for medical journalists to allocate coverage to the studies of immediate relevance to the health of general readers. However, there are several barriers to achieving consensus guidelines. 
First, journal editors may not perceive poor academic press releases as a problem that they have any responsibility to address. Indeed, exaggerated press releases could conceivably benefit journals by increasing citation rates and requests for reprints. ${ }^{10}$ Still, the ultimate mission of journals is to advance the public interest by publishing and publicising good science, and editors should recognise that academic press releases are an important and influential conduit from the journal to the public. Second, even if journals issued consensus guidelines, institutions may have limited capacity to adhere to them. For example, many press releases are now prepared by freelance journalists who may have little or no familiarity with the principles of medical journalism. Nevertheless, journals could still strongly encourage press officers and investigators to revise press releases so that they adhere to consensus guidelines referenced in journals' instructions to authors.

Academic institutions and their faculty share the mission of discovery but also have compelling incentives to maximise publicity for their research accomplishments. One outcome of this motivation is an abundance of academic press releases, too often publicising studies of dubious public health significance. Similarly motivated to maximise publicity, journals currently do nothing to assure the quality of academic press releases. In collaboration with the media and academic institutions, biomedical journals could outline guidelines for the issuance and drafting of academic press releases. These guidelines could specify the characteristics of studies meriting press coverage and critical information for press releases announcing studies of varying designs. Although the guidelines would not wholly prevent the issuance of unmerited or biased press releases, they would comprise a standard to which institutions and authors would be expected to adhere. More judicious academic press releases may result in fewer medical news stories, but the stories reported would better serve the public.

\section{Competing interests None.}

\section{References}

1. Yanovitzky I, Blitz CL. Effect of media coverage and physician advice on utilization of breast cancer screening by women 40 years and older. $J$ Health Commun 2000;5:117-34.

2. Schwitzer G. How do US journalists cover treatments, tests, products, and procedures? An evaluation of 500 stories. PLoS Med 2008;5:e95.

3. Moynihan R, Bero L, Ross-Degnan D, et al. Coverage by the news media of the benefits and risks of medications. $N$ Engl J Med 2000;342:1645-50.

4. Woloshin S, Schwartz LM, Casella SL, et al. Press releases by academic medical centers: not so academic? Ann Intern Med 2009;150:613-18.

5. de Semir V, Ribas C, Revuelta G. Press releases of science journal articles and subsequent newspaper stories on the same topic. JAMA 1998;280:294-5.

6. Schwartz LM, Woloshin S, Andrews A, et al. Influence of medical journal press releases on the quality of associated newspaper coverage: retrospective cohort study. BMJ 2012;344: d8164.

7. Horton R. The lessons of MMR. Lancet 2004;363:747-9.

8. Committee on Publication Ethics. Code of Conduct and Best Practice Guidelines for Journal Editors. 2011. http:// publicationethics.org/files/Code_of_conduct_for_journal_ editors_Mar11.pdf (accessed 29 Aug 2013).

9. Schwitzer G. Statement of principles for health care journalists. PLoS Med 2005;2:e84.

10. Lundh A, Barbateskovic M, Hrobjartsson A, et al. Conflicts of interest at medical journals: the influence of industry-supported randomised trials on journal impact factors and revenue-cohort study. PLoS Med 2010;7:e1000354. 